\title{
Trends in Pulmonary Hypertension Mortality and Morbidity
}

\author{
Alem Mehari, Orlando Valle, and Richard F. Gillum \\ Department of Medicine, Howard University, 2041 Georgia Avenue NW, Washington, DC 20060, USA \\ Correspondence should be addressed to Alem Mehari; alem.mehari@howard.edu \\ and Richard F. Gillum; rfg2.howard.edu@gmail.com
}

Received 18 March 2014; Accepted 14 May 2014; Published 1 June 2014

Academic Editor: Luisetti Maurizio

Copyright (C) 2014 Alem Mehari et al. This is an open access article distributed under the Creative Commons Attribution License, which permits unrestricted use, distribution, and reproduction in any medium, provided the original work is properly cited.

Context. Few reports have been published regarding surveillance data for pulmonary hypertension, a debilitating and often fatal condition. Aims. We report trends in pulmonary hypertension. Settings and Design. United States of America; vital statistics, hospital data. Methods and Material. We used mortality data from the National Vital Statistics System (NVSS) for 1999-2008 and hospital discharge data from the National Hospital Discharge Survey (NHDS) for 1999-2009. Statistical Analysis Used. We present agestandardized rates. Results. Since 1999, the numbers of deaths and hospitalizations as well as death rates and hospitalization rates for pulmonary hypertension have increased. In 1999 death rates were higher for men than for women; however, by 2002, no differences by gender remained because of the increasing death rates among women and the declining death rates among men; after 2003 death rates for women were higher than for men. Death rates throughout the reporting period 1999-2008 were higher for blacks than for whites. Hospitalization rates in women were 1.3-1.6 times higher than in men. Conclusions. Pulmonary hypertension mortality and hospitalization numbers and rates increased from 1999 to 2008.

\section{Introduction}

Pulmonary hypertension $(\mathrm{PH})$ is a disorder of the pulmonary vasculature that results in increased pulmonary arterial pressure and is defined as a mean pulmonary arterial pressure (mPAP) $\geq 25 \mathrm{~mm} \mathrm{Hg}$ at rest, the pressure being measured invasively with a pulmonary artery catheter [1-4]. Despite improvements in the diagnosis and management of $\mathrm{PH}$ over the past 2 decades with the introduction of targeted medical therapies leading to improved survival, the disease continues to have a poor long-term prognosis [5]. US death rates for $\mathrm{PH}$ as the underlying cause of death increased between 1979 and 1999 [6-8]. To assess more recent trends, this report describes national trends for all $\mathrm{PH}$-related deaths and hospitalizations during 1999-2008.

\section{Subjects and Methods}

To examine trends in $\mathrm{PH}$ mortality, we analyzed data from the Centers for Disease Control (CDC) National Vital Statistics System (NVSS). The NVSS classified diseases and conditions reported on death certificates during 1999-2010 according to the International Classification of Diseases, Tenth Revision (ICD-10) codes for deaths [9-19]. For this analysis, we considered PH-associated deaths, those with ICD-10 codes I27.0, I27.8, or I27.9 during 1999-2002 and ICD-10 codes I27.0, I27.2, I27.8, or I27.9 during 2003-2008, as any contributing cause of death (i.e., any of the possible 20 conditions, including underlying cause) on their death certificate. We used resident populations from the U.S. Census Bureau to calculate death rates per 100,000 population. We age-standardized death rates to 2000 U.S. standard population [16, 17]. Because the numbers of deaths with $\mathrm{PH}$ were relatively small each year, we aggregated years according to the availability of drugs for $\mathrm{PH}$, that is, when only epoprostenol was available (1999-2001), after availability of bosentan (2002-2005), and after sildenafil entered the market (2006-2009) to produce stable statistics and shed light on the possible role of these new drugs on mortality and hospitalization.

To examine trends in $\mathrm{PH}$ hospitalization, we analyzed data from the Centers for Disease Control (CDC) National Hospital Discharge Survey (NHDS) for 1999-2009 [20-22]. 
We report estimates of all-listed diagnoses of PH (ICD-9-CM codes 416.0, 416.8, or 416.9) based on counting up to seven medical diagnoses recorded in NHDS and using sampling weights (i.e., inflation factors) that allow estimation of US statistics from the sample.

We used the U.S. civilian population for the period 19992009 from the U.S. Census Bureau to calculate age- and sexspecific diagnosis rates per 100,000 population. To examine trends in diagnoses during 1999-2009, we aggregated data into one 3-year and two 4-year periods (1999-2001, 20022005) and (2006-2009) as for mortality (see above).

Supplementary Material provides detailed tables not included in this report. (See Supplementary Tables in the Supplementary Material available online at http://dx.doi.org/ $10.1155 / 2014 / 105864)$.

\section{Results}

3.1. Mortality. During 1999-2008, the total number of deaths with $\mathrm{PH}$ listed as any contributing cause of death increased from 15,046 in 1999 to 19,373 in 2008. For the reporting periods 1999-2002 and 2003-2008, 57.7\% and 61\%, respectively, of decedents with $\mathrm{PH}$-related mortality were female. In $1999-2002,11.2 \%$ of males and $9.7 \%$ of females were $<45$ years; in $2003-2008,8.4 \%$ of males and $6.9 \%$ of females were aged $<45$ years. The proportion of decedents aged $\geq 85$ years increased from $17.6 \%$ to $22.4 \%$. At all ages in $1999-$ 2008, the most common underlying cause of death was pulmonary hypertension (29.4-30.8\%), followed by chronic lower respiratory disease (20.2-27.0\%). Among decedents aged $<45$ years, the most common underlying causes of death were $\mathrm{PH}$; congenital malformations; complications of pregnancy, childbirth, and the puerperium; or conditions originating in the perinatal period. Supplementary Material provides further detailed mortality data in supplementary Tables 1-9.

In 1999-2008, age-standardized death rates for the total U.S. population remained relatively stable from 1999 through 2008 (Table 1). However, age-standardized death rates increased among women; among men rates decreased during 1999-2006 then increased during 20072008 (Figure 1). Rates increased with age. Blacks had higher rates than whites for each year in the reporting period. Non-Hispanics had higher age-standardized death rates than Hispanics. There was an upward trend in age-specific death rates for people aged $\geq 85$ years, most markedly during 2006-2008. In 1999-2001, men had slightly higher age-specific death rates than women, but in 2002-2008 women had higher age-specific death rates than men in the older age groups. At ages <75 years, blacks had higher age-specific death rates than whites during 1999-2001, but whites had higher death rates than blacks at ages $\geq 85$ years. States with the 10 highest age-standardized death rates were Vermont (11.4), Wyoming (10), Colorado (8.9), Idaho (7.9), DC (7.7), Montana (7.5), North Carolina (7.5), Ohio (7.5), West Virginia (7.3), and New Mexico (7.4). Supplementary Material provides further detailed hospitalization data in supplementary Tables 10-13.

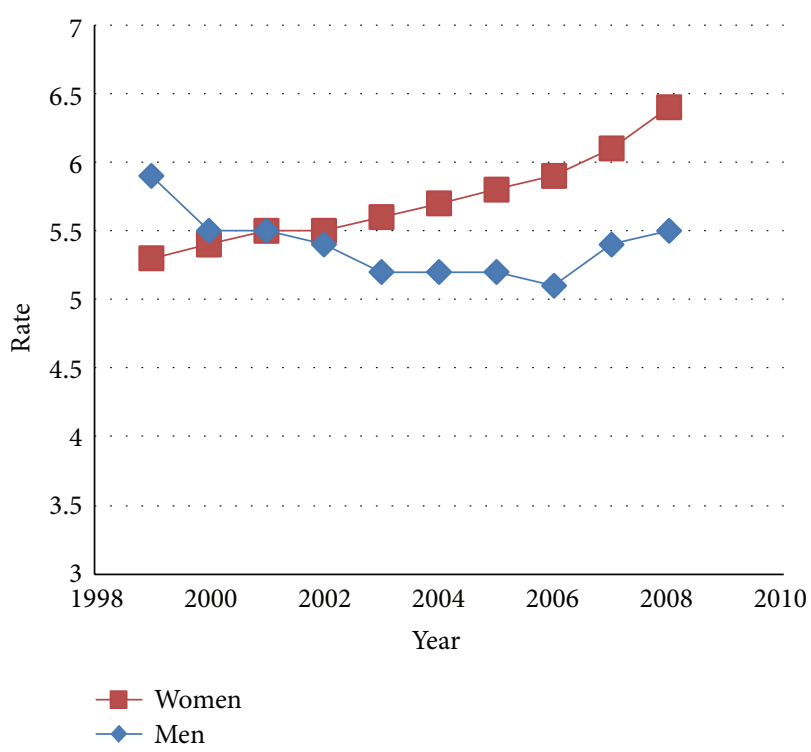

Figure 1: Age-standardized death rate per 100,000 population for decedents with pulmonary hypertension listed as any contributing cause of death by sex and year-United States 1999-2008. Age is standardized using the 2000 U.S. standard population.

TABle 1: Age-standardized and age-specific death rates* for pulmonary hypertension $^{\dagger}$ as any contributing cause of death for groups defined by selected characteristics and by period: United States, 1999-2008.

\begin{tabular}{lccc}
\hline Characteristic & 1999-2001 & 2002-2005 & 2006-2008 \\
\hline Age-standardized ${ }^{\dagger \dagger}$ death rate & & & \\
All & 5.5 & 5.5 & 5.8 \\
$\quad$ Men & 5.6 & 5.3 & 5.3 \\
$\quad$ Women & 5.4 & 5.7 & 6.1 \\
Race & & & \\
$\quad$ Black & 7.4 & 7.6 & 8.1 \\
$\quad$ White & 5.3 & 5.3 & 5.6 \\
$\quad$ Asian/Pacific Islander & 2.6 & 2.5 & 2.8 \\
$\quad$ American Indian & 4.0 & 3.9 & 3.9 \\
Hispanic origin & & & \\
Hispanic & 3.2 & 3.1 & 3.1 \\
$\quad$ Non-Hispanic & 5.6 & 5.7 & 5.9 \\
Age-specific death rate & & & \\
0-44 yrs & 0.9 & 0.8 & 0.7 \\
45-54 yrs & 2.8 & 2.7 & 2.8 \\
55-64 yrs & 7.2 & 7.0 & 7.0 \\
65-74 yrs & 19.4 & 19.0 & 18.3 \\
75-84 yrs & 37.1 & 39.0 & 43.0 \\
>85 yrs & 60.8 & 67.4 & 80.0 \\
\hline
\end{tabular}

${ }^{*}$ Per 100,000 population; ${ }^{\dagger}$ International Classification of Diseases, Tenth Revision Codes I27.0, I27.2, I27.8, and I27.9; ${ }^{\dagger \dagger}$ to the 2000 U.S. standard population.

3.2. Hospitalizations. From 1999 to 2009 , the estimated number of all-listed diagnoses of $\mathrm{PH}$ increased by 1.5 times from 257 thousand to 386 thousand. Women accounted for 
$59.3-60.3 \%$ and patients aged $\geq 65$ years accounted for $62.6-$ $66.7 \%$ of all-listed diagnoses of $\mathrm{PH}$. All-listed diagnosis rates in 2006-2009 were 1.2-1.4 times higher in men and 1.5 times higher in women than earlier (Table 2). The rate of all-listed diagnoses increased for all age groups; the greatest increase was among adults aged $\geq 65$ years. Rates of diagnoses for $\mathrm{PH}$ among women were higher than those for men throughout the study period (Figure 2). Rates increased with age. Rates were highest in the northeast region.

\section{Discussion}

During 1999-2008, rates for $\mathrm{PH}$ as any contributing cause of death and as all-listed hospital diagnoses increased. The number of $\mathrm{PH}$-related deaths and number of hospitalizations increased, particularly among women, blacks, and older adults. In addition, $\mathrm{PH}$ was the most common reported underlying cause of death among all decedents with $\mathrm{PH}$ as any contributing cause of death during 2000-2008. PH might have been diagnosed more often as diagnostic and therapeutic options improve. Increased survival of patients with $\mathrm{PH}$ receiving more effective therapy over the last two decades could also play a role.

The observed increases in reporting of $\mathrm{PH}$ as anylisted diagnosis on hospital records might indicate an actual increase in the number of patients or, more likely, a greater awareness among physicians. Increased awareness of $\mathrm{PH}$ as a fatal condition could lead to increased reporting of $\mathrm{PH}$ as a contributing cause of death $[23,24]$. Even though patients with $\mathrm{PH}$ die due to right heart failure, heart failure is rarely reported on $\mathrm{PH}$ death certificates as the underlying cause because specific instructions on the death certificate state that "cardiac failure" should not be listed as the underlying cause of death.

Although the question cannot be directly addressed with these data, one may wish to consider the possible effect on $\mathrm{PH}$ mortality and hospitalizations of the introduction of new drugs for $\mathrm{PH}$, namely, epoprostenol sodium, followed by bosentan and sildenafil to the US market. Epoprostenol (for injection) was approved for $\mathrm{PH}$ by the United States Food and Drug Administration (FDA) in 1995. Bosentan (oral) was approved for $\mathrm{PH}$ by the United States Food and Drug Administration (FDA) in 2001. Sildenafil (for injection and oral) is marketed for $\mathrm{PH}$ and was approved for PH by the United States Food and Drug Administration (FDA) in 2005 (Source Pulmonary Hypertension Association, http://www.phassociation.org/Treatments, last accessed 5/13/2014). These data are consistent with increased availability of approved drugs for the treatment of $\mathrm{PH}$, some given by infusion, contributing to increased rates of hospitalization and listing of $\mathrm{PH}$ discharge diagnoses in the most recent period shown in Table 2 (2006-2009). Increasing frequency of premortem diagnoses also could have led to increased listing of $\mathrm{PH}$ as a contributing cause of death on death certificates leading to apparent increases in rates over the period shown in Table 1.

Our findings are similar to those of Davis et al., who suggested that annual age-adjusted mortality for idiopathic
TABLE 2: Estimated rate $^{*}$ of pulmonary hypertension ${ }^{\dagger}$ all-listed diagnoses during hospital stay, by selected characteristics and period: National Hospital Discharge Survey, United States, 19992009.

\begin{tabular}{lccc}
\hline Characteristic & $\begin{array}{c}1999-2001 \\
\text { rate }^{*}\end{array}$ & $\begin{array}{c}\text { 2002-2005 } \\
\text { rate* }^{*}\end{array}$ & $\begin{array}{c}\text { 2006-2009 } \\
\text { rate }^{*}\end{array}$ \\
\hline Total & 96.3 & 90.8 & 115.1 \\
Male & 79.7 & 74.1 & 93.4 \\
Female & 112.2 & 106.9 & 135.4 \\
15-44 years & 14.1 & 18.3 & 20.2 \\
45-64 years & 103.4 & 104.5 & 100.0 \\
65 and over & 527.2 & 453.0 & 598.7 \\
Northeast & 120.8 & 103.4 & 132.6 \\
Midwest & 99.0 & 92.0 & 112.6 \\
South & 90.6 & 91.3 & 122.1 \\
West & 79.3 & 78.1 & 92.6 \\
\hline
\end{tabular}

${ }^{*}$ Per 100,000 population; ${ }^{\dagger}$ International Classification of Diseases, Ninth Revision, Clinical Modification codes 416.0, 416.8, and 416.9.

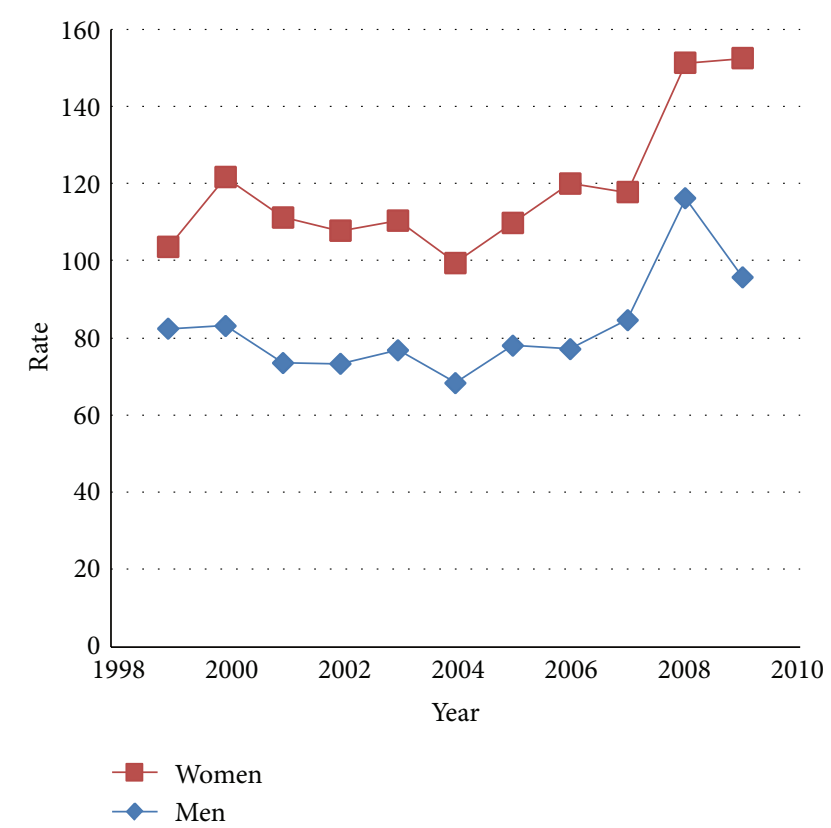

FIGURE 2: Estimated annual rate per 100,000 population of all-listed diagnoses of pulmonary hypertension by year and sex: National Hospital Discharge Survey, United States, 1999-2009.

pulmonary arterial hypertension increased between 19791996 and 1994-1998, the greatest increase was among black women and that the disease may not be uncommon in the elderly $[6,8]$. Similarly, Hyduk et al. observed increasing rates of hospitalizations for $\mathrm{PH}$ and mortality with $\mathrm{PH}$ over the period 1980-2002, particularly among women, blacks, and older adults. In their report, $30 \%$ of the patients dying with $\mathrm{PH}$ were 75 years of age or older [7]. In addition, age-specific death rates for $\mathrm{PH}$ increased among men 65 years of age or older, whites 75 years of age or older, and blacks 65 years of 
age or older. Similar to our report, during 1990-2002 death rates were higher for blacks than whites. The proportion of patients dying with $\mathrm{PH}$ who were 75 years of age or older increased from 1980 to $2002 ; 30.6 \%$ of all patients dying with $\mathrm{PH}$ from 2000 to 2002 were 75 to 84 years of age, and $18.1 \%$ were 85 years of age or older, compared with $23.7 \%$ and $6.5 \%$, respectively, from 1980 to 1984 [7]. Hence, these results combined with our results indicate long-term trends that may be expected to continue during the remainder of this decade. It will be important to learn what portion of the trends is due to increased physician awareness and changes in diagnosis and reporting.

Estimates for prevalence of idiopathic pulmonary arterial hypertension cannot be ascertained from our report. However, registry data suggest that the average age and percent female have increased in the last two decades [2527]. In the Registry to Evaluate Early and Long-term Pulmonary Arterial Hypertension Disease Management, mean age at diagnosis was 47 years and $78 \%$ were female. Possible explanations for the increased female predominance include increased representation in the US population of ethnic groups (e.g., blacks, Hispanics) with a higher female: male ratio in patients with $\mathrm{PH}$, increased environmental or iatrogenic and hormonal influences (particularly estrogens) in the pathogenesis of $\mathrm{PH}$, and the increasing prevalence of severe obesity [28]. Another possible explanation is gender difference in health seeking behavior for reporting health problems and seeking treatment. A survivor bias may also exist with a greater proportion of female patients living longer or responding better to therapy [29]. Explanations for the older age include a change in the population age distribution, in the natural history of the disease itself (e.g., a change in some unrecognized intrinsic or extrinsic factor that delays disease manifestations), improved survival with therapy, or an increased prevalence of chronic lung disease in women due to secular trends in smoking among women. Our findings of excess $\mathrm{PH}$ mortality in blacks are generally consistent with the association between race and excess mortality from disease of the circulatory system in the United States [30]. Mechanisms for gender and racial differences in $\mathrm{PH}$ occurrence have been reviewed elsewhere [30, 31].

The highest hospital diagnosis rate was observed in the Northeast United States and highest death rates for PH were observed in Vermont and in the Rocky Mountain Western United States (Colorado, Idaho, Montana, New Mexico, and Wyoming). Possible explanations for this geographic pattern include the following: first, these cases might be more likely to be detected by physicians affiliated with $\mathrm{PH}$ centers that are located in Denver (CO) and Philadelphia (PA). Second, altitude might also play an important role in the development of $\mathrm{PH}$ in states such as Colorado, Montana, and Wyoming [6-8]. Identification of these patterns warrants further investigations.

Our study has several limitations. First, mortality data are subject to diagnosis and reporting errors by physicians, medical examiners, and coroners. Second, the current ICD classifications do not allow data users to differentiate specific diseases that are associated with $\mathrm{PH}$. For example, the current ICD codes do not allow differentiation of the five major categories of $\mathrm{PH}[2,3]$. Thus, population estimates for WHO group I pulmonary arterial hypertension cannot be ascertained, a category of interest to researchers. Finally, hospital discharge data cannot be used to estimate prevalence or incidence of the disease because distinguishing between first hospitalizations or readmissions during the year is not possible and some patients may not be hospitalized. However, the NVSS and NHDS databases are useful for surveillance and monitoring trends.

\section{Conflict of Interests}

The authors declare that there is no conflict of interests regarding the publication of this paper.

\section{Acknowledgments}

The authors acknowledge the helpful comments by Rosanna Setse, M.D., Ph.D., Thomas O. Obisesan, M.D., M.P.H., Alicia N. Thomas, M.D., Alvin Thomas Jr., M.D., Octavius Polk, M.D., Wayne P. Davis, M.D., and Patricia O’Neal, M.D.

\section{References}

[1] D. B. Badesch, H. C. Champion, M. A. Gomez Sanchez et al., "Diagnosis and assessment of pulmonary arterial hypertension," Journal of the American College of Cardiology, vol. 54, no. 1, supplement, pp. S55-S66, 2009.

[2] G. Simonneau, N. Galiè, L. J. Rubin et al., "Clinical classification of pulmonary hypertension," Journal of the American College of Cardiology, vol. 43, no. 12, supplement, pp. 5S-12S, 2004.

[3] G. Simonneau, I. M. Robbins, M. Beghetti et al., "Updated Clinical Classification of Pulmonary Hypertension," Journal of the American College of Cardiology, vol. 54, no. 1, supplement 1, pp. S43-S54, 2009.

[4] N. F. Voelkel, R. A. Quaife, L. A. Leinwand et al., "Right ventricular function and failure: report of a National Heart, Lung, and Blood Institute working group on cellular and molecular mechanisms of right heart failure," Circulation, vol. 114, no. 17, pp. 1883-1891, 2006.

[5] V. V. McLaughlin, "Looking to the future: a new decade of pulmonary arterial hypertension therapy," European Respiratory Review, vol. 20, no. 122, pp. 262-269, 2011.

[6] K. K. Davis, D. E. Lilienfeld, and R. L. Doyle, "Increased mortality in African Americans with idiopathic pulmonary arterial hypertension," Journal of the National Medical Association, vol. 100, no. 1, pp. 69-72, 2008.

[7] A. Hyduk, J. B. Croft, C. Ayala, K. Zheng, Z.-J. Zheng, and G. A. Mensah, "Pulmonary hypertension surveillance-United States, 1980-2002," MMWR Surveillance Summaries, vol. 54, no. 5, pp. $1-28,2005$.

[8] D. E. Lilienfeld and L. J. Rubin, "Mortality from primary pulmonary hypertension in the United States, 1979-1996," Chest, vol. 117, no. 3, pp. 796-800, 2000.

[9] J. Link, C. Glazer, F. Torres, and K. Chin, "International classification of diseases coding changes lead to profound declines in reported idiopathic pulmonary arterial hypertension mortality and hospitalizations: implications for database studies," Chest, vol. 139, no. 3, pp. 497-504, 2011. 
[10] S. Rich, E. Chomka, L. Hasara et al., "The prevalence of pulmonary hypertension in the United States. Adult population estimates obtained from measurements of chest roentgenograms from the NHANES II Survey," Chest, vol. 96, no. 2, pp. 236-241, 1989.

[11] R. N. Anderson, A. M. Miniño, D. L. Hoyert, and H. M. Rosenberg, "Comparability of cause of death between ICD9 and ICD-10: preliminary estimates," National Vital Statistics Reports, vol. 49, no. 2, pp. 1-32, 2001.

[12] G. R. Bramer, "International statistical classification of diseases and related health problems. Tenth revision," World Health Statistics Quarterly, vol. 41, no. 1, pp. 32-36, 1988.

[13] E. Weitzenblum, "Chronic cor pulmonale," Circulation, vol. 27, no. 4, pp. 594-615, 1963.

[14] "MANUAL of the international statistical classification of diseases, injuries, and causes of death. Addendum 1. Supplementary interpretations and instructions for coding causes of death," Bulletin of the World Health Organization. Supplement, vol. 7, supplement 6, pp. 1-55, 1953.

[15] "The international conference for the tenth revision of the International Classification of Diseases. Strengthening of Epidemiological and Statistical Services Unit. World Health Organization, Geneva," World Health Statistics Quarterly, vol. 43, no. 4, pp. 204-245, 1990.

[16] R. N. Anderson and H. M. Rosenberg, "Age standardization of death rates: implementation of the year 2000 standard," National Vital Statistics Reports, vol. 47, no. 3, pp. 1-16, 20, 1998.

[17] R. J. Klein and C. A. Schoenborn, "Age adjustment using the 2000 projected U.S. population," Healthy People 2000 Statistical Notes, no. 20, pp. 1-9, 2001.

[18] Centers for Disease Control and Prevention, National Center for Health Statistics, Underlying Cause of Death 1999-2009 on CDC WONDER Online Database, 2012, http://wonder.cdc.gov/ucd-icd10.html.

[19] National Center for Health Statistics, National Vital Statistics System, US Department of Health and Human Services, CDC, National Center for Health Statistics, Hyattsville, Md, USA, 2009, http://www.cdc.gov/nchs/nvss.htm.

[20] W. R. Simmons and G. A. Schnack, Development of the Design of the NCHS Hospital Discharge Survey. Vital Health Statistics, series 2, no. 39, DHEW publication no. (HRA) 77-1199, Human Resources Administration, Rockville, Md, USA, 1977, http://www.cdc.gov/nchs/data/series/sr_02/sr02_039.pdf.

[21] L. J. Kozak, Underreporting of Race in the National Hospital Discharge Survey, Advance data no. 265, US Department of Health and Human Services, CDC, National Center for Health Statistics, Hyattsville, Md, USA, 1995, http://www.cdc.gov/nchs/ data/ad/ad265.pdf.

[22] US Department of Health and Human Services. The International Classification of Diseases, Ninth Revision, Clinical Modification, DHHS publication no. (PHS) 91-1260, US Department of Health and Human Services, CDC, National Center for Health Statistics, Health Care Financing Administration, Hyattsville, Md, USA, 4th edition, 1991.

[23] D. Mukerjee, D. St George, B. Coleiro et al., "Prevalence and outcome in systemic sclerosis associated pulmonary arterial hypertension: application of a registry approach," Annals of the Rheumatic Diseases, vol. 62, no. 11, pp. 1088-1093, 2003.

[24] R. A. Israel, H. M. Rosenberg, and L. R. Curtin, "Analytical potential for multiple cause-of-death data," The American Journal of Epidemiology, vol. 124, no. 2, pp. 161-179, 1986.
[25] D. B. Badesch, G. E. Raskob, C. G. Elliott et al., "Pulmonary arterial hypertension: baseline characteristics from the REVEAL registry," Chest, vol. 137, no. 2, pp. 376-387, 2010.

[26] A. E. Frost, D. B. Badesch, R. J. Barst et al., "The changing picture of patients with pulmonary arterial hypertension in the United States: how REVEAL differs from historic and non-US contemporary registries," Chest, vol. 139, no. 1, pp. 128-137, 2011.

[27] G. E. D’Alonzo, R. J. Barst, S. M. Ayres et al., "Survival in patients with primary pulmonary hypertension: results from a national prospective registry," Annals of Internal Medicine, vol. 115, no. 5, pp. 343-349, 1991.

[28] K. M. Flegal, D. Carroll, B. K. Kit, and C. L. Ogden, "Prevalence of obesity and trends in the distribution of body mass index among US adults, 1999-2010," Journal of the American Medical Association, vol. 307, no. 5, pp. 491-497, 2012.

[29] M. Humbert, O. Sitbon, A. Chaouat et al., "Survival in patients with idiopathic, familial, and anorexigen-associated pulmonary arterial hypertension in the modern management era," Circulation, vol. 122, no. 2, pp. 156-163, 2010.

[30] A. T. Geronimus, J. Bound, T. A. Waidmann, M. M. Hillemeier, and P. B. Burns, "Excess mortality among blacks and whites in the United States," The New England Journal of Medicine, vol. 335, no. 21, pp. 1552-1558, 1996.

[31] E. D. Austin, T. Lahm, J. West et al., "Gender, sex hormones and pulmonary hypertension," Pulmonary Circulation, vol. 3, no. 2, pp. 294-314, 2013. 


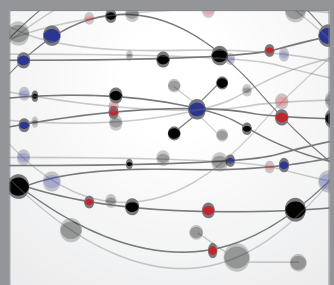

The Scientific World Journal
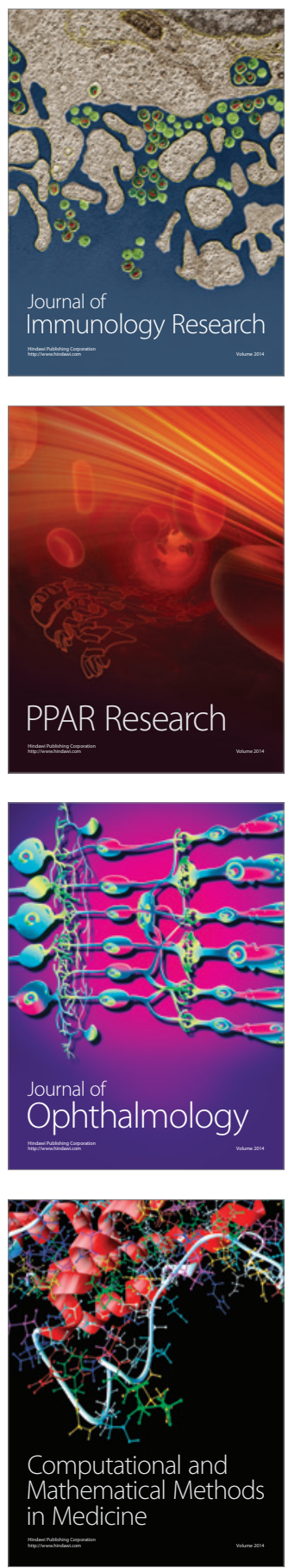

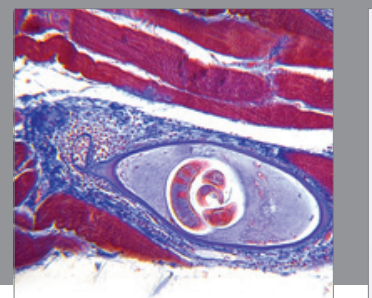

Gastroenterology

Research and Practice
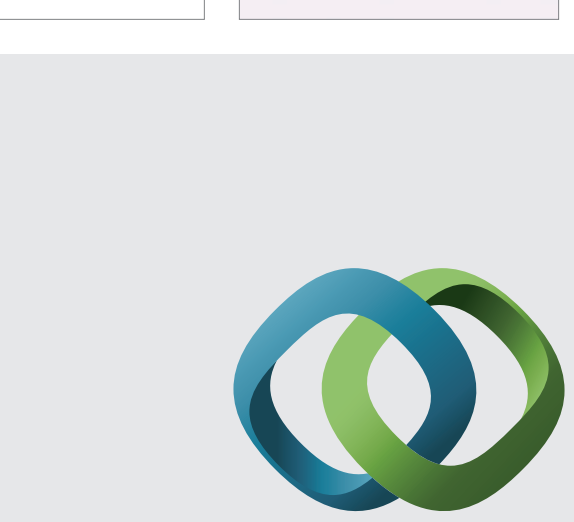

\section{Hindawi}

Submit your manuscripts at

http://www.hindawi.com
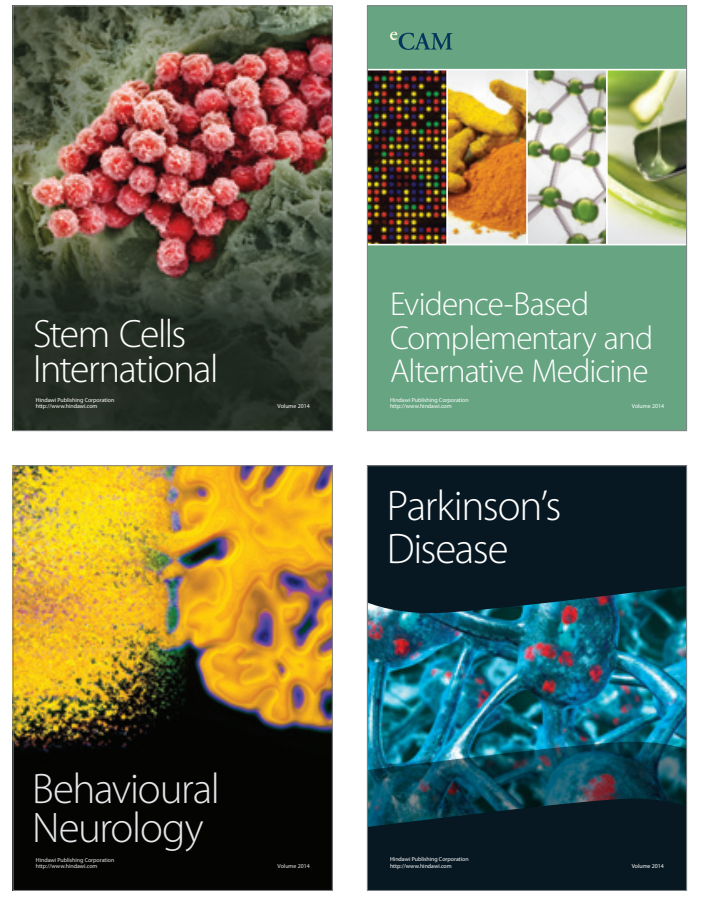
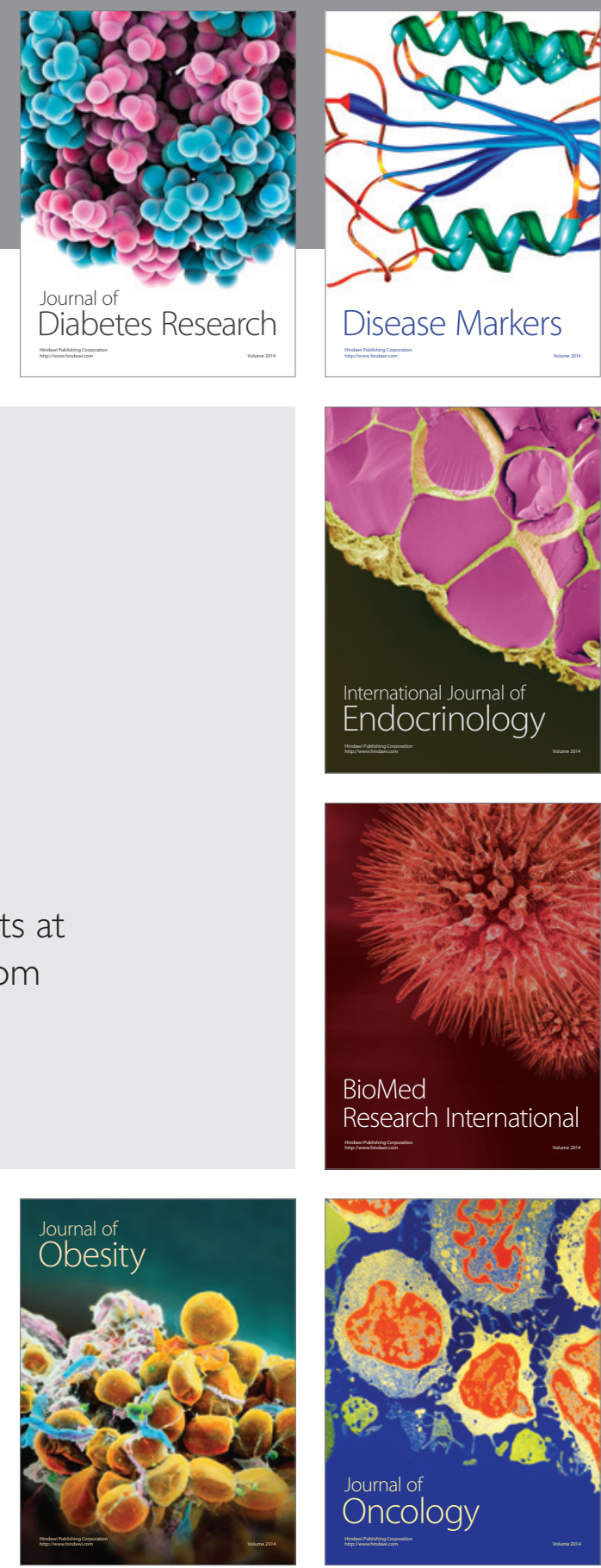

Disease Markers
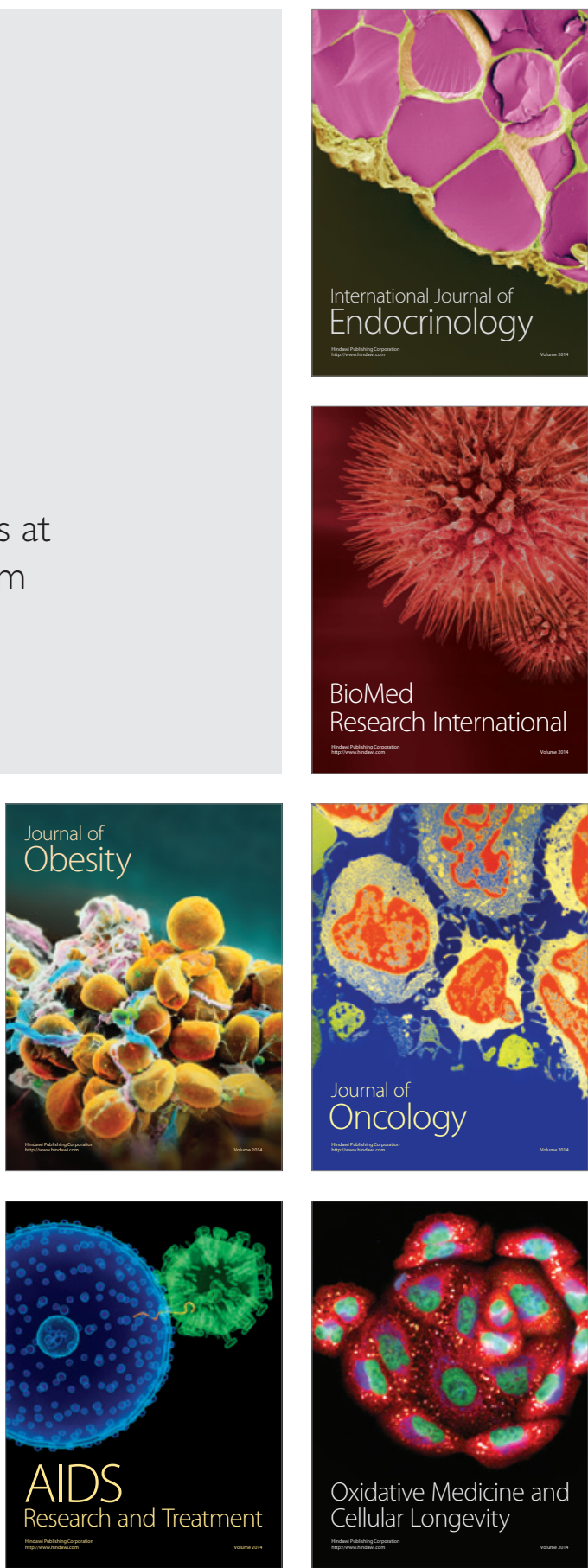